\title{
JOURNAL OF ADVANCED MEDICAL AND PHARMACEUTICAL RESEARCH
}

Received $14^{\text {th }}$ January 2021 , Accepted $16^{\text {th }}$ February 2021 Published $14^{\text {th }}$ March 2021

jampr.journals.ekb.eg

Online ISSN: $2636-4158$

\section{C-X-C Chemokine Receptor-3 as a Diagnostic Biomarker in Patients with Rheumatoid Arthritis}

\author{
Mohamed R. Salama', Hanan H. Omar ${ }^{2}$, Samah I. Nasef ${ }^{3}$, Amany H. Hamed ${ }^{1 *}$, \\ Azza M. Abdallah ${ }^{4}$ \\ ${ }^{1}$ Department of Chemistry, Faculty of Science, Sohag University, Sohag 82111, Egypt \\ ${ }^{2}$ Department of Clinical Pathology, Faculty of Medicine, Suez Canal University, Ismailia 41111, Egypt \\ ${ }^{3}$ Department of Physical Medicine, Rheumatology, and Rehabilitation, Faculty of Medicine, Suez Canal University, Ismailia 41111, Egypt \\ ${ }^{4}$ Department of Chemistry, Faculty of Science, Suez Canal University, Ismailia 41111, Egypt
}

\begin{abstract}
Background: Rheumatoid Arthritis (RA) is a chronic and systemic inflammatory disease characterized by synovial inflammation and the progressive destruction of joint ligaments and bones. CXCR3 is a seven-transmembrane G-protein-coupled chemokine receptor that has been appeared to play a vital role in a variety of inflammatory and immunological responses. We aimed to evaluate the utility of serum $\mathrm{C}-\mathrm{X}-\mathrm{C}$ chemokine receptor 3 (CXCR3) levels in the diagnosis, monitor, and follow-up of RA patients. Methods: Sixty RA patients were divided into 30 early RA patients with disease duration $<2$ years and 30 longstanding RA patients with disease duration $\geq 2$ years. Thirty healthy subjects were recruited as a control group. Medical history and clinical data were taken. All the patients were assessed for erythrocyte sedimentation rate (ESR), C-reactive protein (CRP), rheumatoid factor (RF), anti-cyclic citrullinated peptide (anti-CCP), and CXCR3 serum levels. Results: Serum CXCR3 level was significantly elevated in RA patients compared to healthy normal controls with a highly statistically significant difference $(p<0.001)$. The serum levels of CXCR3 were elevated in long-standing RA more than early RA. Serum level of CXCR3 was only positively correlated with the duration of disease $(r=0.540, p=>0.001)$ and combined treatment $(r=0.296, p=0.022)$. Receiver operating characteristic $(R O C)$ curves were plotted for the prediction of serum CXCR3 in RA patients. The best cut-off value that indicates the presence of early RA disease is $4.026 \mathrm{ng} / \mathrm{mL}$ serum CXCR3 with $71.7 \%$ sensitivity and $70 \%$ specificity ( $\mathrm{p}=$ 0.005). Conclusion: Serum CXCR3 is an imperative predictive biomarker for the diagnosis of RA, an indicator for early RA disease, and endorses the established RA disease.
\end{abstract}

Keywords: Biomarker, Chemokine, Receptor, Prediction, Rheumatoid arthritis.

\section{INTRODUCTION}

Rheumatoid arthritis (RA) is a chronic and systemic inflammatory disease characterized by synovial inflammation

\footnotetext{
* Department of Chemistry, Faculty of Science, Sohag University, Sohag, Egypt, 82511, Tel.: 01150088375.

E-mail address: hamde_r2001@yahoo.com
}

and the progressive destruction of joint ligaments and bones. ${ }^{1}$ RA synovial tissue is regularly described by synovial hyperplasia, also called pannus, which is penetrated with inflammatory cells. The synovial pannus in RA produces proinflammatory cytokines, chemokines, and proteases, including monocytes and $\mathrm{B}$ and $\mathrm{T}$ lymphocytes, attacks and destroys cartilage and bone. ${ }^{2}$ In addition, fibroblast-like synoviocytes (FLS) have a central role in synovial pannus formation and joint destruction in RA. ${ }^{3}$ 
The process of leukocyte attack into inflammatory sites is basic for the initiation and progression of a variety of inflammatory disorders and is controlled through the activation and motioning of particular cell surface chemoattractant receptors by their related protein ligands, named chemokines. ${ }^{4}$ Furthermore, the migration of $\mathrm{T}$ cells to destinations of aggravation is mediated by selectins and their ligands. ${ }^{5}$ The guideline of leukocyte relocation is organized by initiating cytokines and adhesion molecules. Other than that, the enrollment of leukocytes to locales of irritation is driven and mediated by the effects of chemo-attractants. ${ }^{6}$

It has been demonstrated that $\mathrm{T}$ helper1 (Th1) and T helper2 (Th2) cells respond differently to several chemokines and express different chemokine receptors. $\mathrm{C}-\mathrm{X}-\mathrm{C}$ chemokine receptor 3 (CXCR3) is a seven-transmembrane G-proteincoupled chemokine receptor that has appeared to play a vital role in a variety of inflammatory and immunological responses. Particularly, the CXCR3 receptor is chiefly expressed on the activated Th1 cells. ${ }^{7}$

RA is a constant immune system illness depicted by steady synovitis. Since chemotactic cytokines (chemokines) may play critical roles in the enlistment of leukocytes in RA, investigation for the expression of chemokines and their receptors should provide insight into events in synovial irritation of RA. ${ }^{8,9}$

Chemokines have a strong significant role in joint inflammation, not only by inducing leukocyte chemotaxis but also by activating immune cells and angiogenesis. ${ }^{10}$ It was demonstrated that the expanded articulation of Th1-related cytokines in cells of synovial liquid and synovial tissue guessed that Th1 cells may play an active role in the development of autoimmune responses in RA. ${ }^{11}$

Therefore, the purpose of this study was to evaluate the utility of serum CXCR3 levels in the diagnosis, monitor, and follow-up of RA patients.

\section{MATERIALS AND METHODS}

\subsection{Patients}

Patients with RA, who were diagnosed by ACR/EULAR (2010) Classification Criteria for RA, ${ }^{12}$ have been recruited from the Rheumatology and Rehabilitation department. The study was performed on sixty RA patients. They were divided into 30 early RA patients with disease duration $<2$ years and 30 longstanding RA patients with disease duration $\geq 2$ years. Thirty healthy subjects were recruited as a control group. Informed consents were taken from each patient and control. The study was approved by the Medical Ethics Committee.

\subsection{Blood specimen collection and clinical data}

Clinical information collection included disease duration, medication history, duration of morning stiffness, and body mass index (BMI). Clinical assessment of disease activity was done by evaluating the following parameters: swollen joint includes in 28 joints (SJC 28), tender joint includes in 28 joints status (TJC 28), C-reactive protein (CRP), or erythrocyte sedimentation rate (ESR), patient global health on a 0 to 10 scale. High disease activity is considered when disease activity score of 28 joints (DAS 28) is above 5.1, moderate diseases activity between 3.2 and 2.6, and low disease activity below 2.6. All the RA patients were under medical treatment as methotrexate (MTX), hydroxychloroquine (HCQ), leflunomide, and steroid. There were no patients under biological treatment.

Lab examinations included rheumatoid factor (RF) and anti-cyclic citrullinated peptide (anti-CCP). Quantitative detection of the CXCR3 level in the serum of the patients and control was done. Serum was isolated from whole blood via density gradient centrifugation at $4^{\circ} \mathrm{C}$ within 4 hours of blood collection and promptly saved into 200 all aliquots at $-80^{\circ} \mathrm{C}$ till experimentation.

\subsection{Measurement of serum CXCR3 level}

Serum CXCR3 concentrations were estimated by sandwich enzyme-linked immunosorbent assay (ELISA) kit, from Bio kit (Quantikine human CXC3, Shanghai Sunred Biological Technology Co., Ltd). The outcomes are naturally determined to utilize the straight-line regression equation of the standard curve with the standard density and the OD values and are expressed in $\mathrm{ng} / \mathrm{mL}$. This examination has high sensitivity and excellent specificity for the detection of CXCR3. No significant cross-reactivity or interference among CXCR3 and analogs was observed. The sensitivity of the CXCR3 level measurement range extends from $0.05 \mathrm{ng} / \mathrm{mL}$ to $15 \mathrm{ng} / \mathrm{ml}$.

\subsection{Statistical analysis}

Analysis of data was performed by IBM PC using statistical package for social science (SPSS) version 25. Data had been expressed as mean, standard deviation (SD), frequencies, and percentages were utilized to describe qualitative variables. The comparison between two groups with parametric variables was done using independent sample t-test (t). ANOVA test was utilized to assess the statistical significance of the difference between more than two study group means. The correlation coefficient between two parametric parameters was calculated by using Pearson and Spearman correlation coefficient. A Chi-Square test was used to examine the relationship among two qualitative variables. The receiver operating characteristic (ROC) curve provides a useful way to evaluate the sensitivity and specificity for quantitative diagnostic measures that categorize cases into one of two groups. In all tests if $(p>0.05)$ it is non-significant, if $(p<0.05)$ it is significant and if $(p<0.001)$ it is highly significant.

\section{RESULTS}

The studied groups were age and gender-matched. Group 1 included $30 \mathrm{RA}$ patients with disease duration $<2$ years, they were 27 females $(90.0 \%)$ and 3 males $(10.0 \%)$, they had a mean age of $40.60 \pm 11.99$ years. Group 2 included 30 RA patients with disease duration $\geq 2$ years, they were 28 females (93.3\%) and 2 males (6.7\%), they had a mean age of 
$45.43 \pm 9.17$ years. The control group included 30 normal subjects, 27 females $(90.0 \%)$ and 3 males $(10.0 \%)$, they had a mean age of $42.87 \pm 9.31$ years.

In this study, there was no statistically significant difference between early and long-standing RA patients regarding family history, BMI, number of tender joints, number of swollen joints, and treatment. Moreover, there was no statistically significant difference between early and longstanding RA patients regarding RF, Anti-CCP, CRP, ESR, DAS28.CRP and DAS28.ESR (Table 1).

Table 1: Clinical and laboratory data of the studied RA patients

\begin{tabular}{|c|c|c|c|}
\hline Characteristics & $\begin{array}{l}\text { Early RA } \\
(\mathbf{n}=\mathbf{3 0})\end{array}$ & $\begin{array}{l}\text { Long-standing } \\
\text { RA } \\
(\mathrm{n}=30) \\
\end{array}$ & p-value \\
\hline $\begin{array}{l}\text { Duration of disease }(\mathrm{yrs})^{\#} \\
\text { Mean } \pm \text { SD }\end{array}$ & $1.30 \pm .431$ & $10.06 \pm 7.25$ & $<0.001^{*}$ \\
\hline $\begin{array}{l}\text { Family History }{ }^{@} \\
\text { Negative } \\
\text { Positive }\end{array}$ & $\begin{array}{l}21(70 \%) \\
9(30 \%)\end{array}$ & $\begin{array}{c}23(76.7 \%) \\
7(23.3 \%)\end{array}$ & 0.559 \\
\hline $\begin{array}{l}\text { BMI kg/m² } \# \\
\text { Mean } \pm \text { SD }\end{array}$ & $29.92 \pm 5.79$ & $29.03 \pm 3.99$ & 0.488 \\
\hline $\begin{array}{l}\text { No. of tender joint }{ }^{\#} \\
\text { Mean } \pm \text { SD } \\
\text { No. of swelling joint }{ }^{\#}\end{array}$ & $10.30 \pm 8.82$ & $10.72 \pm 9.82$ & 0.862 \\
\hline $\begin{array}{l}\text { Mean } \pm \text { SD } \\
\text { Treatment No. }(\%)^{@}\end{array}$ & $1.83 \pm 2.11$ & $2.24 \pm 4.25$ & 0.641 \\
\hline $\begin{array}{l}\text { MTX } \\
\text { MTX and HCQ } \\
\text { MTX, HCQ and steroid } \\
\text { Leflunomide }\end{array}$ & $\begin{array}{l}10(36.7 \%) \\
7(23.3 \%) \\
6(16.7 \%) \\
7(23.3 \%)\end{array}$ & $\begin{array}{l}10(33.3 \%) \\
12(40 \%) \\
4(13.3 \%) \\
4(13.3 \%)\end{array}$ & 0.451 \\
\hline $\begin{array}{l}\text { Rheumatoid } \\
\text { factor }(\mathbf{I U} / \mathbf{m L}) \\
\text { Mean } \pm \text { SD }\end{array}$ & $49.98 \pm 55.5$ & $46.73 \pm 35.4$ & 0.788 \\
\hline $\begin{array}{l}\text { Rheumatoid factor } \\
\text { Positive No. }(\%) \\
\text { Negative No. }(\%)\end{array}$ & $\begin{array}{l}20(66.7 \%) \\
10(33.3 \%)\end{array}$ & $\begin{array}{c}24(80 \%) \\
6(20 \%)\end{array}$ & 0.243 \\
\hline $\begin{array}{l}\text { Anti-CCP }(\mathrm{U} / \mathrm{mL}) \\
\text { Positive No. }(\%) \\
\text { Negative No. }(\%)\end{array}$ & $\begin{array}{l}12(40 \%) \\
18(60 \%)\end{array}$ & $\begin{array}{l}19(63.3 \%) \\
11(36.7 \%)\end{array}$ & 0.071 \\
\hline CRP $(\mathrm{mg} / \mathrm{L})$ Mean $\pm \mathrm{SD}$ & $15.19 \pm 17.17$ & $14.83 \pm 15.95$ & 0.933 \\
\hline ESR $(\mathrm{ml} / \mathrm{hr})$ Mean \pm SD & $54.73 \pm 27.23$ & $59.07 \pm 31.48$ & 0.571 \\
\hline DAS28.CRP Mean \pm SD & $4.39 \pm 1.52$ & $5.15 \pm 1.79$ & 0.082 \\
\hline DAS28.ESR Mean \pm SD & $5.12 \pm 1.60$ & $4.91 \pm 1.61$ & 0.607 \\
\hline
\end{tabular}

*\#Quantitative data are represented by Mean \pm SD and tested by $\mathrm{t}$ test, @Qualitative data represented by chi-Square Test. *Statistically-significant $\mathrm{p}<0.05 ; \mathrm{BMI}=$ Body mass index. MTX=Methotrexate; $\mathrm{HCQ}=$ Hydroxychloroquine; Anti-CCP: Antibody to cyclic citrullinated peptide; CRP: C reactive protein; ESR: erythrocyte sedimentation rate; DAS28: Disease Activity Score 28 joints.

Serum CXCR3 level was significantly elevated in RA patients compared to healthy normal controls with a highly statistically significant difference $(p<0.001)$ (Figure $1)$. The serum levels of CXCR3 were elevated in Longstanding RA more than early RA (Table 2 ).

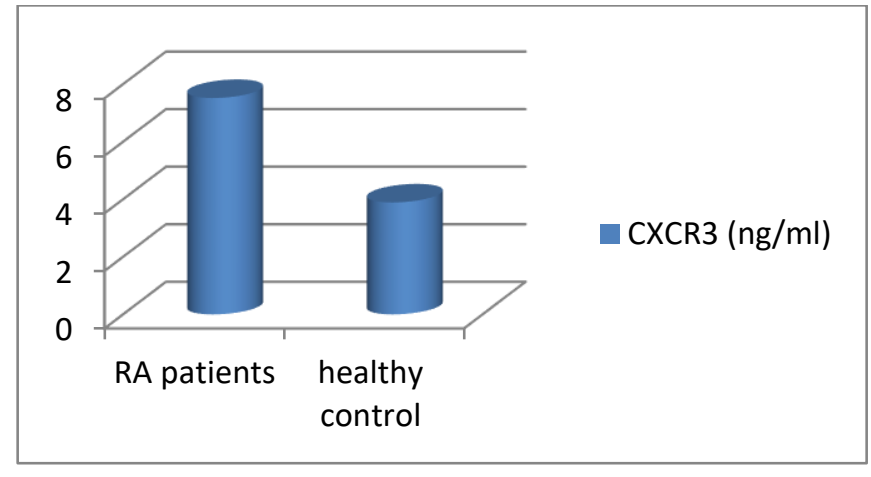

Figure 1: Serum levels of CXCR3 in RA patients and healthy control.

Table 2: serum levels of CXCR3 in early, longstanding RA patients and healthy control.

\begin{tabular}{lclll}
\hline Variable & $\begin{array}{c}\text { Early RA } \\
(\mathbf{n = 3 0})\end{array}$ & $\begin{array}{l}\text { Long-standing } \\
\text { RA } \\
(\mathbf{n}=\mathbf{3 0})\end{array}$ & $\begin{array}{l}\text { Healthy } \\
\text { control } \\
(\mathbf{n = 3 0})\end{array}$ & p-value \\
\hline $\begin{array}{l}\text { CXCR3 } \\
(\mathbf{n g} / \mathbf{m L})\end{array}$ & $5.37 \pm 2.39$ & $9.68 \pm 6.32$ & $3.89 \pm 3.57$ & $<0.001^{*}$ \\
\hline
\end{tabular}

$* \mathrm{p}<0.05$ is statistically-significant.

Serum level of CXCR3 was only positively correlated with the duration of disease $(\mathrm{r}=0.540, \mathrm{p}=<0.001)$ and combined treatment $(\mathrm{r}=0.296, \mathrm{p}=0.022)$. The serum level of CXCR3 had no correlation with other studied clinical and laboratory parameters (Table 3 ).

Table 3: Correlation of RA patients' parameters with - serum CXCR3 level.

\begin{tabular}{lcc}
\hline \multirow{2}{*}{ Characteristics } & \multicolumn{2}{c}{ CXCR3 } \\
\cline { 2 - 3 } & R & p-value \\
\hline Age & 0.065 & 0.543 \\
BMI & 0.02 & 0.879 \\
Duration of disease (years) & 0.540 & $<0.001^{*}$ \\
CRP & 0.120 & 0.361 \\
ESR & 0.048 & 0.715 \\
DAS28.CRP & 0.133 & 0.309 \\
DAS28.ESR & 0.103 & 0.433 \\
Anti-CCP & 0.019 & 0.887 \\
No. of tender joint & 0.086 & 0.518 \\
No. of swelling joint & 0.077 & 0.565 \\
Rheumatoid factor & -.180 & 0.168 \\
Treatment (combined) & 0.296 & $0.022 *$ \\
\hline
\end{tabular}

$* \mathrm{p}<0.05$ is not statistically significant.

ROC curves were plotted for the prediction of serum CXCR3 in RA patients. The first ROC curve was plotted for the prediction of RA disease from healthy persons. The best cut-off value that indicates the presence of RA disease was $5.567 \mathrm{ng} / \mathrm{mL}$ serum CXCR3 with $60 \%$ sensitivity and $75 \%$ 
specificity $(p=<0.001)$. Another ROC curve was plotted for serum CXCR3 to indicate the presence of early RA sets a threshold value of $4.026 \mathrm{ng} / \mathrm{mL}$ with $71.7 \%$ sensitivity and $70 \%$ specificity $(\mathrm{p}=0.005)$. Additionally, the ROC curve for serum CXCR3 for the prediction of establishing RA in RA patients was done. The best cut-off value that indicates the presence of established RA disease was $6.246 \mathrm{ng} / \mathrm{mL}$ serum CXCR3 with $60 \%$ sensitivity and $67.7 \%$ specificity $(\mathrm{p}=$ $<0.035$ ) (Figure 2).

To establish a logistic regression model to evaluate the diagnostic efficacy of RF, anti-CCP, and CXCR3 for early RA, we ran binary logistic regressions with early RA and healthy control as our dependent variable. The area under the curve (AUC) was established to evaluate the diagnostic ability of RF, anti-CCP, CXCR3, and their combined diagnostic ability. The AUC, sensitivity, and specificity values of RF were $0.699,66 \%$ and $77 \%$ respectively, while those of antiCCP were $0.742,73 \%$ and $77 \%$ respectively, and those of
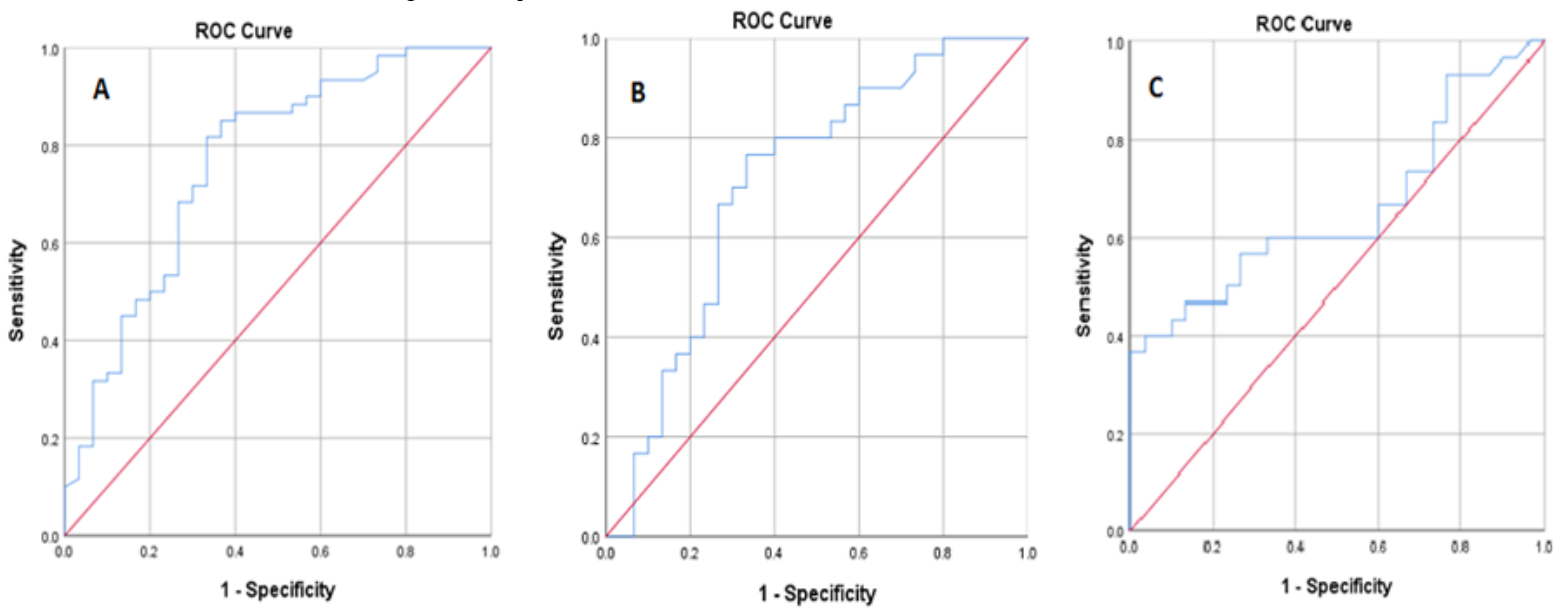

Figure 2: ROC curves for serum CXCR3. A: for prediction of RA disease from healthy persons. B: for prediction of early RA from healthy persons; $\mathbf{C}$ : for prediction of established RA disease in RA patients.

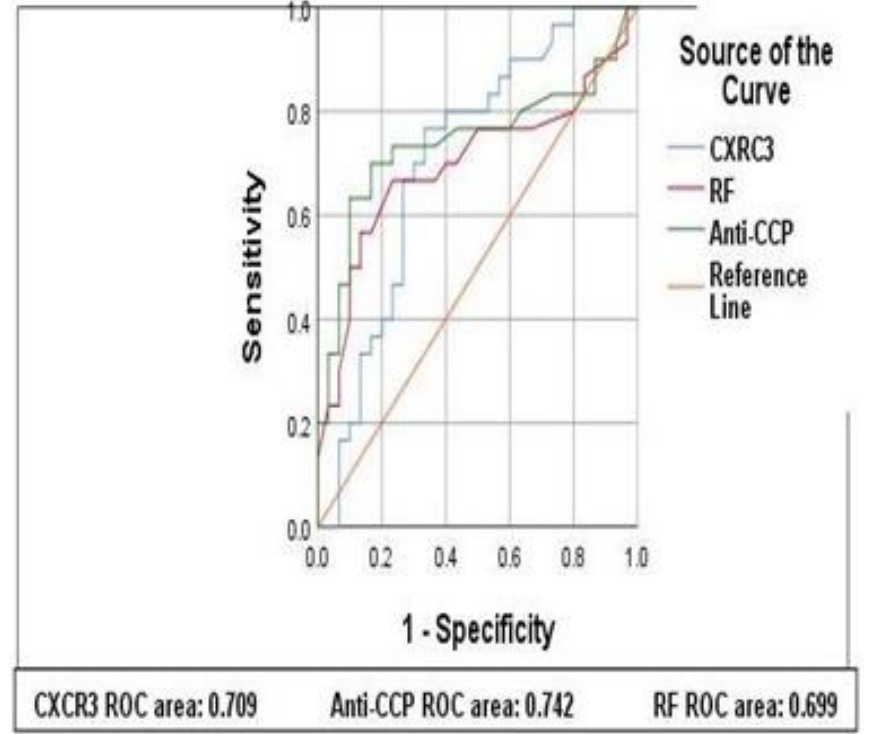

Figure 3: Comparative receiver operating characteristic (ROC) analysis for RF, anti-CCP, and CXCR3. The ROC-curves for tests were comparable as shown by the area under the curve (AUC) values.
CXCR3 were $0.709,71 \%$ and $70 \%$ respectively. The AUC value of anti-CCP is higher than that of RF and CXCR3. Anti$\mathrm{CCP}$ sensitivity is higher than RF and CXCR3, but the specificity of RF and anti-CCP is higher than CXCR3. Combined, anti-CCP and CXCR3 had the best AUC, sensitivity, and specificity, therefore the combined diagnosis by RF, anti-CCP, and CXCR3 is an effective model for the diagnosis of early RA (Figure 3).

The logistic regression models were followed up by ROC curves to evaluate their combined diagnostic ability. As can be observed in (Figure 4), combining RF, anti-CCP, and CXCR3 yields an AUC value of 0.859 indicating an acceptable discriminating power of the model (Figure 4).

Finally, in order to investigate which combination of RF, Anti-CCP, and CXCR3 values leads to a higher probability of having early RA.

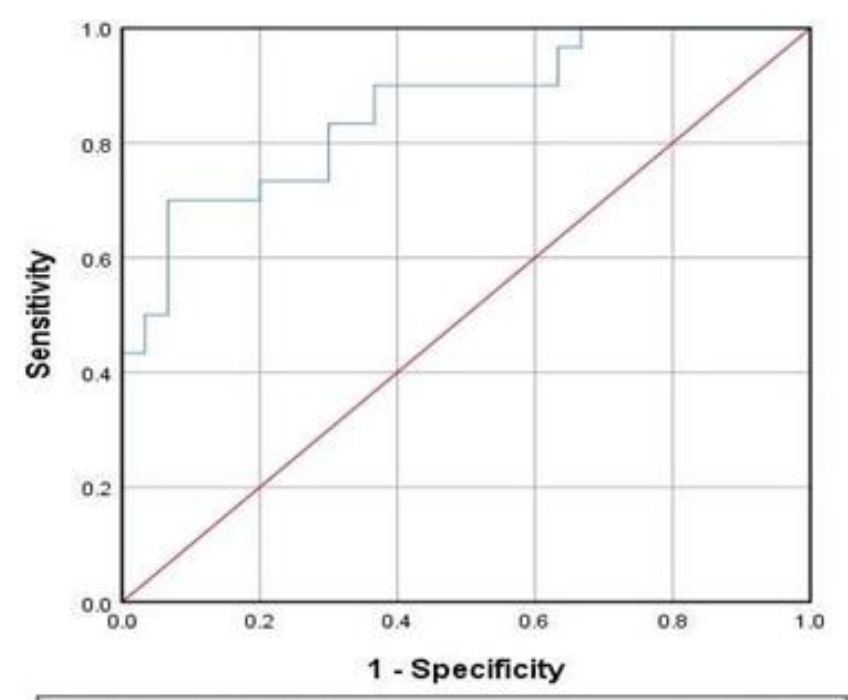

RF, Anti-CCP and CXCR3 area under ROC curve $=0.859$

Figure 4: ROC-curve after logistic regression analysis, RF, anti$\mathrm{CCP}$ and CXCR3. 


\section{DISCUSSION}

RA, as an autoimmune disease, causes pain, swelling, and stiffness in the joints, and may cause severe joint damage, loss of function, and disability. RA is a condition affecting around $2 \%$ of the population. ${ }^{13,14}$

Chemokines and their receptors are molecules that may manage the selective migration of particular $\mathrm{T}$-cell subsets. In other investigations, additional expression of CXCR3 was detected in endothelial cells and dendritic cells, as well as in eosinophils within Th1 dominated tissues, including RA synovial tissue. ${ }^{15}$ CXCR3 plays an important role during various inflammatory diseases such as psoriasis, rheumatoid arthritis, and also during infection. ${ }^{16}$

In the current study, the measured serum level of CXCR3 was significantly higher in RA patients (early and long-standing RA) compared to healthy control. Collectively, our findings were in line with El-Barbary et al., ${ }^{17}$ they mentioned that CXCR3 levels in peripheral blood were found to be increased in RA patients compared with controls. Similarly Motoki et al., ${ }^{18}$ they noted that the expression of CXCR3 on peripheral blood CD4+ T lymphocytes of RA patients was significantly higher than healthy controls. In agreement with the study by Ruschpler et al., ${ }^{15}$ who also illustrated that receptor CXCR3 was significantly increased in RA patients compared to osteoarthritis (OA) patients. Similarly, Henneken et al., ${ }^{19}$ they reported that levels of CXCR3 were demonstrated to be increased in RA patients when compared with healthy individuals.

In the current study, there was no correlation between BMI and serum level of CXCR3. Our results differed from those of the study by Shoda et al., ${ }^{20}$ who showed that the concentration of CXCR3 correlated with BMI. An association between excess body weight and different inflammatory/autoimmune conditions has been proposed in numerous observational studies. ${ }^{21}$ Excess body weight was considered as a potential supporter to the development of RA. $^{22}$

Interestingly, our results also revealed that there was a positive correlation between the disease duration of RA and the serum levels of CXCR3 with a high statistical significant difference, disease duration was used as a predictor of vascular stiffness in RA patients, ${ }^{23}$ and in agreement with Lleo et al. ${ }^{24}$ who found positive correlation between CXCR3 expression in CD4+ T cells and disease duration, as well as with Motoki et al., ${ }^{18}$ who found that the CXCR3 expression in RA patients with long-term disease duration was significantly higher than in those with the short-term disease.

In our work, there was no correlation between serum levels of CXCR3 and CRP as well as ESR. This was in accordance with the study done by Motoki et al., ${ }^{18}$ who found that CXCR3 was not correlated with CRP. In contrast to our results, Wang et al., ${ }^{25}$ found a positive significant correlation between The expression levels of CXCR3 mRNA and serum levels of ESR as well as CRP in the clinically active RA group. Similarly, Sun et al., ${ }^{26}$ found that the levels of CXCR3 were significantly correlated with CRP.

In the present study, serum levels CXCR3 did not show any significant correlation with DAS28.CRP and
DAS28.ESR. On contrary with our result, the study by ElBarbary et al., ${ }^{17}$ reported that CXCR3 has a positive correlation with multiple disease activity measures including DAS-28 scores, CRP, ESR, swollen and tender joint counts in 28 joints. Similarly, the study by Lee et al., ${ }^{24}$ showed the CXCR3 has the strongest correlations with disease activity.

Our study reported that there was no correlation between serum levels of CXCR3 and the number of tender and swollen joints in RA patients. In contrast to Aldridge et al., ${ }^{27}$ who found a negative correlation between CXCR3 and swollen joint counts of 28 and 66 joints.

In the current study, it was observed that there was no significant correlation between serum CXCR3 level in RA patients with RF and anti-CCP. RF was the primary autoantibody to be found in people with RA. Despite the name, however, RF is not particular to RA. Almost $20 \%$ of those with confirmed RA will not have an abnormal RF test, whereas 5\% of individuals who do not have RA will have an abnormal RF test. Negative levels do not exclude the disease, and positive levels do not ensure the diagnosis Song Kang. ${ }^{28}$

In agreement with our results, El-Barbary et al., ${ }^{17}$ found that RF titer had no significant correlation with the expression levels of CXCR3 in RA patients. In contrast to our findings, the study by Paulissen et al., ${ }^{29}$ found that CXCR3 level was higher in ACPA+ RA than ACPA- RA patients.

The accuracy of serum CXCR3 to discriminate RA cases from the normal population was evaluated using ROC curve analysis. According to our data, CXCR3 could diagnose and discriminate RA patients at different points through the course of the disease.

This enables the physician to follow up with the patients and choose the appropriate and suitable management.

\section{CONCLUSION AND RECOMMENDATIONS}

Serum CXCR3 is an imperative predictive biomarker for the diagnosis of RA, and is an indicator for early RA disease and endorses the established RA disease. According to our study, we recommend: (1) More studies are needed to clarify that CXCR3 plays a central role in RA inflammation and may serve as a disease activity marker in established RA. (2) Clinical trials are needed to explore the beneficial effects of therapeutic targeting of CXCR3 in RA.

\section{ETHICS APPROVAL AND CONSENT TO PARTICIPATE}

All authors have seen and approved the manuscript, contributed significantly to the work, and also that the manuscript has not been previously published in or is not being considered for publication elsewhere. The study was approved by the Ethics Committee.

\section{CONFLICTS OF INTREST}

The authors declare no conflict of interest. 


\section{FUNDING}

This research did not receive any specific grant from funding agencies in the public, commercial or not-for-profit sectors.

\section{REFERENCES}

1. G. S. Firestein, and I. B. McInnes, Immunity, 2017, 46, 183-196.

2. I. Sudoł-Szopińska, E. Kontny, W. Maśliński, M. Prochorec-Sobieszek, B. Kwiatkowska, K. ZaniewiczKaniewska, and A. Warczyńska, J. Ultrason., 2012, 12, 202-213.

3. B. Bartok, and G. S. Firestein, Immunol. Rev., 2010, 233, 233-255.

4. M. M. Wong, and E. N. Fish, Semin. Immunol., 2003, 15, 5-14.

5. P. Rajendran, in Frontiers in Anti-Cancer Drug Discovery, ed. Atta-ur-Rahman and M. I. Choudhary, Bentham Science Publishers Pte. Ltd., Singapore, 2019, vol. 10, ch. 4, pp. 62-110.

6. S. Nourshargh, and R. Alon, Immunity, 2014, 41, 694707.

7. M-R. Du, S-C. Wang, and D-J. Li, Cell. Mol. Immunol., 2014, 11, 438-448.

8. X. Chen, J. J. Oppenheim, and O. Howard, Cell. Mol. Immunol., 2004, 1, 336-342.

9. S. Sharif, N. Ueda, Y. Nakatani, L. M. Wise, S. Clifton, Z. Lateef, A. A. Mercer, and S. B. Fleming, Front. microbiol., 2019, 10, 1421.

10. J. L. Owen, and M. Mohamadzadeh, Front. physiol., 2013, 4, 159.

11. A. Jäger, and V. K. Kuchroo, Scand. J. Immunol., 2010, 72, 173-184.

12. D. Aletaha, T. Neogi, A. J. Silman, J. Funovits, D. T. Felson, C. O. Bingham 3rd, N. S. Birnbaum, G. R. Burmester, V. P. Bykerk, M. D. Cohen, B. Combe, K. H. Costenbader, M. Dougados, P. Emery, G. Ferraccioli, J. M. W. Hazes, K. Hobbs, T. W. J. Huizinga, A. Kavanaugh, J. Kay, T. K. Kvien, T. Laing, P. Mease, H. A. Ménard, L. W. Moreland, R. L. Naden, T. Pincus, J. S. Smolen, E. Stanislawska-Biernat, D. Symmons, P. P. Tak, K. S. Upchurch, J. Vencovský, F. Wolfe, and G. Hawker, Arthritis Rheum., 2010, 62, 2569-2581.

13. C. L. Gorman, and A. P. Cope, Best Pract. Res. Clin. Rheumatol., 2008. 22, 221-238.

14. T. Iwamoto, H. Okamoto, and Y. Toyama, S. Momohara, FEBS J., 2008, 275, 4448-4455.

15. P. Ruschpler, P. Lorenz, W. Eichler, D. Koczan, C. Hänel, R. Scholz, C. Melzer, H-J. Thiesen, and P. Stiehl, Arthritis Res. Ther., 2003, 5, R241-R252.

16. J. E. Ehlert, C. A. Addison, M. D. Burdick, S. L. Kunkel, and R. M. Strieter, J. Immunol., 2004, 173, 6234-6240.

17. A. El-Barbary, S. Essa, and H. Zaytoun, Egypt. Rheumatol. Rehabil., 2013, 40, 75-80.

18. Y. Motoki, K. Tani, T. Shimizu, H. Tamiya, K. Hase, Y. Ohmoto, K. Matsushima, and S. Sone, Mod. Rheumatol., 2003, 13, 114-120.
19. M. Henneken, T. Dörner, G-R. Burmester, and C. Berek, Arthritis Res. Ther., 2005, 7, R1001-R1013.

20. H. Shoda, Y. Nagafuchi, Y. Tsuchida, K. Sakurai, S. Sumitomo, K. Fujio, and K. Yamamoto, Arthritis Res. Ther., 2017, 19, 111.

21. M. Versini, P-Y. Jeandel, E. Rosenthal, and Y. Shoenfeld, Autoimmun. Rev., 2014, 13, 981-1000.

22. D. P. M. Symmons, Rheumatology, 2005, 44, iv14-iv17.

23. M. Vázquez-Del Mercado, E. Gomez-Bañuelos, E. Chavarria-Avila, E. Cardona-Muñoz, C. Ramos-Becerra, A. Alanis-Sanchez, D. Cardona-Muller, F. Grover-Paez, F. de J Perez-Vazquez, R-E. Navarro-Hernandez, J. M. Valadez-Soto, A. A. Saldaña-Millan, L. Gonzalez-Rosas, G. Ramos-Lopez, M. H Petri, and M. Bäck, Medicine, 2017, 96, e7862.

24. A. Lleo, W. Zhang, M. Zhao, Y. Tan, F. Bernuzzi, B. Zhu, Q. Liu, Q. Tan, F. Malinverno, L. Valenti, T. Jiang, L. Tan, W. Liao, R. Coppel, P. Invernizzi, Q. Lu, D. H. Adams, M. E. Gershwin, and the PBC Epigenetic Study Group, Clin. Epigenetics, 2015, 7, 61.

25. G. Wang, L. Shi, Y. Mengxue, L. Shen, W. Gou, L. Guo, and F. Xue, Chin. J. Rheumatol., 2010, 14, 627-630.

26. S. Sun, Y. Chen, Z. Zhang, W. Zhang, L. Zuo, and G. Xiang, The Journal of Practical Medicine, 2014, 18, 2902-2904.

27. J. Aldridge, J. M. Pandya, L. Meurs, K. Andersson, I. Nordström, E. Theander, A-C. Lundell, and A. Rudin, Arthritis Res. Ther., 2018, 20, 150.

28. Y. Song, and E. H. Kang, QJM, 2010, 103, 139-146.

29. S. M. J. Paulissen, J. P. van Hamburg, N. Davelaar, H. Vroman, J. M. W. Hazes, P. H. P. de Jong, and E. Lubberts, Arthritis Res. Ther., 2015, 17, 344. 